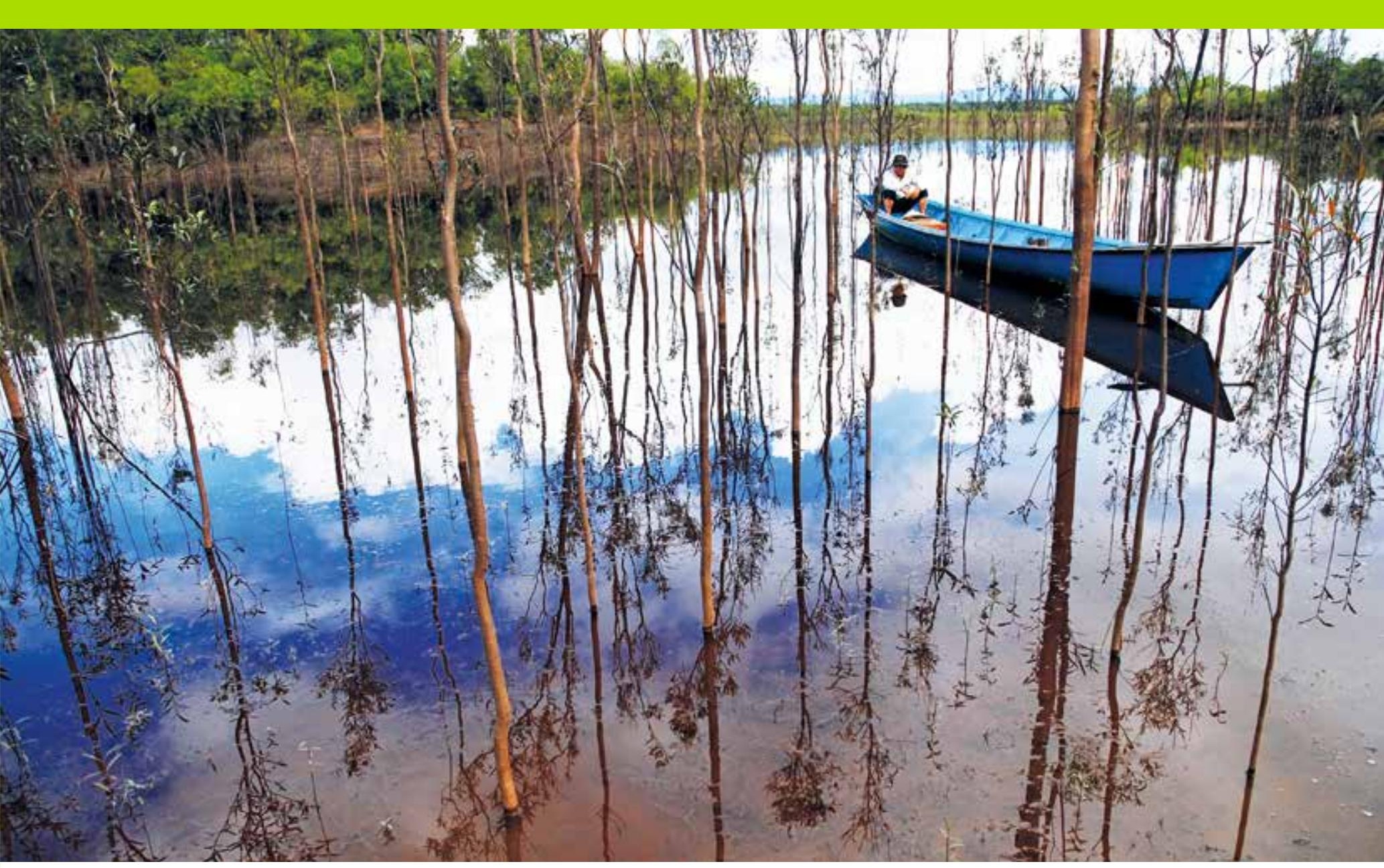

\title{
Code book for the analysis of media frames in articles on REDD
}

Global Comparative Study on REDD (GCS-REDD)

Component 1 on National REDD+ Policies and Processes

Monica Di Gregorio

Stephan Price

Clare Saunders

Maria Brockhaus

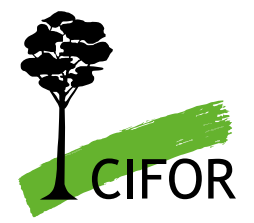



Global Comparative Study on REDD (GCS-REDD)

Component 1 on National REDD+ Policies and Processes

\section{Code book for the analysis of media frames in articles on REDD}

Monica Di Gregorio

Stephan Price

Clare Saunders

Maria Brockhaus 
(C) 2012 Center for International Forestry Research All rights reserved

Di Gregorio, M., Price, S.H., Saunders, C.E. and Brockhaus, M. 2012 Code book for the analysis of media frames in articles on REDD. CIFOR, Bogor, Indonesia.

Cover photo by Ryan Woo

West Kalimantan, Indonesia.

CIFOR

Jl. CIFOR, Situ Gede

Bogor Barat 16115

Indonesia

$\mathrm{T}+62(251) 8622-622$

$\mathrm{F}+62$ (251) 8622-100

Ecifor@cgiar.org

\section{cifor.org}

Any views expressed in this publication are those of the authors. They do not necessarily represent the views of CIFOR, the authors' institutions or the financial sponsors of this publication. 


\section{Table of contents}

1 Introduction 1

1.1 Media framing 1

1.2 Defining primary and secondary frames 1

1.3 Procedure 1

2 Code book $\quad 4$

Variables and codes: Derivations and meaning 4

2.1 Descriptive variables $\quad 4$

2.2 Variables analysing the primary and secondary frames 5

2.3 Protest event analysis 12

$\begin{array}{ll}2.4 \text { Policy event analysis } & 13\end{array}$

2.5 Policy actor list $\quad 14$

3 References 14

$\begin{array}{ll}\text { Acknowledgements } & 14\end{array}$ 



\section{Introduction}

\subsection{Media framing}

A media frame is "a broad organising theme for selecting, emphasising, and linking the elements of a story such as the scenes, the characters, their actions, and supporting documentation" (Bennet cited in 2002: 42 cited in Boykoff 2008). In practice a frame is a conceptual lens that brings certain aspects of reality into sharper focus (emphasising a particular way to understand an issue) while relegating others to the background.

Boykoff uses media analysis to investigate media framing of climate change in the US and the UK (Boykoff 2007, 2008: Boykoff and Mansfield 2008). This code book draws on his approach and provides specific adaptation for issues related to reducing emissions from deforestation and forest degradation, and enhancing forest carbon stocks in developing countries (REDD+).

\subsection{Defining primary and secondary frames}

News articles can be broken down into a number of sections. The first few paragraphs are likely to add to, and reinforce, the message offered in the headline, while later paragraphs often take up the story from a slightly different angle, returning to the original theme later on. This means that longer news stories will not just have one frame, but possibly several. Although Boykoff (2008) makes little distinction between them, identifying primary and secondary frames enables assessment of the comparative importance given to different understandings of a topic by journalists and editors. Boykoff (2008) states that identifying the different levels of frames 'was contingent on salience of elements in the text, who was quoted and/or referred to, terms used, and relationships between clusters of messages'. We outline below what this means to us in practical terms.

In practice, it is most straightforward to identify the primary frame first. These will always be found in most prominent elements of the text: headline, subheading and first paragraph. However, we should be aware that the headline may not always match the opening paragraph exactly, as different people are responsible for headlines (editors) and articles (journalists). In this case, we need to make a careful decision about which element is most powerful in framing the article. The primary frame is also likely to quote sources in support of the frame; these are more likely to be named, and more likely to be prestigious, than in subsidiary frames. For the sake of 'balance' the frame is likely to include a rebuttal, or alternative view from that initially proposed. However, adversaries are often given less prominence, space and direct voice than 'primary definers' (the term given to the chief advocate of the primary frame).

Having eliminated the elements of the text that support the primary frame, we can then group the remaining text according to themes and assess their position in the text, and the nature and extent of quoted sources, to identify a secondary frame. Shorter articles are less likely to consist of more than one frame.

\subsection{Procedure}

The media frames code book is divided in five sections and allows for three different depths of coding and analysis. A flexible research design can allow for Level 3 coding to be applied to all or a subsample of articles, depending on the total number of relevant articles.

\subsubsection{Translation of the codebook}

National teams will be responsible for translating the code book, attention should be given to locally used language when translating terms.

\subsubsection{Newspaper selection}

The team should identify three major national newspapers to be used in the media analysis. The three newspapers should be selected from among those with the highest circulation and should reflect a broad spectrum of political positions in the country. At the discretion of the team, it is possible to add one or two regional newspapers in case REDD+ debates and decisions are regionally specific (e.g. in the case of federal systems, such as Brazil, or administrative regions which are particularly relevant for REDD+ policies and have substantial autonomy in policy decisions, such as Papua in Indonesia. This is not necessary if it is likely that major regional debates are captured in the national media. 
It is assumed that journal articles are available in electronic and possibly searchable form. Otherwise, the news company might have archives catalogued in other ways, which could be useful to identify relevant articles. This should be verified in advance and might affect the selection of newspapers.

\subsubsection{Selection of articles}

The first task is to identify and retrieve all articles since December 2005 (Conference of the Parties 11 -Montreal meeting) that focus on 'climate change' or 'REDD', which is the most popular keyword in Internet searches. The selection can be undertaken through a search on the following keywords:

- 'climate change' OR

- 'global warming' OR

- 'Kyoto Protocol' OR

- 'climate change AND forest' OR

- 'REDD' OR

- 'reduced emissions from deforestation and forest degradation' (exact phrase) ${ }^{1}$ OR

- 'avoided deforestation' (exact phrase)

The country team should translate and indigenise the above keywords to reflect nationally used terms corresponding to the English keywords. The objective here is to retrieve most articles that substantively discuss climate change or REDD issues.

An 'and/or search' should be used, so that an article is picked up if it mentions one or more of the keywords. Some search engines have the capacity to use a 'Boolean' search criteria that permits searching for articles that contain either/or 'climate change', 'REDD', 'reduced emissions from deforestation and forest degradation', and 'avoided deforestation'.

The search is best undertaken in the title, or abstract, or first paragraph of articles from selected newspapers. It is important to document the actual search procedure used in the report, so that this is clear to the reader, and can be taken into account for comparative purposes.

1 The shorter phrases 'emissions from deforestation and forest degradation' and 'emissions from deforestation' can also be considered. It is important though to avoid duplication of search results.
The result will be a collection of articles about 'climate change' or 'REDD'. Next, these articles must be divided into three categories, and recorded in the table below.

\begin{tabular}{ll}
\hline Keywords & $\begin{array}{l}\text { Total number } \\
\text { of articles }\end{array}$ \\
\hline 'Climate change' & $\mathrm{X}$ \\
\hline 'Climate change AND forest' & $\mathrm{Y}$ \\
\hline $\begin{array}{l}\text { 'REDD' OR'reduced emissions from } \\
\text { deforestation and forest degradation' } \\
\text { OR'Avoided deforestation'2 }\end{array}$ & $\mathrm{Z}$ \\
\hline
\end{tabular}

Only the articles on REDD (resulting from the 'REDD' OR 'reduced emissions from deforestation and forest degradation' OR 'avoided deforestation' keyword searches) are coded.

\subsubsection{Database for REDD articles}

Article_ID. Each article that is entered in the database must be given a unique identifying and date-oriented number. This should be entered one line before the article. The identity code is as follows: year/month/day/newspaper abbreviation/ page number of article. If two or more articles appear on the page a letter can be added to indicate the order: a, b, c (e.g. 20090101JP1a). This will be used as the 'Article_ID' variable in the Level 1 coding (see below).

Data file. All documents should be stored in order of their identity numbers in a single long text file or Microsoft Word file. Several text files can be made if one gets too long, but a single file can hold hundreds or perhaps even thousands of documents.

Data backup. Backup copies must be kept of all data files, and backed up often.

\subsubsection{Coding}

Initial date range of articles. Since the Center for International Forestry Research (CIFOR) project focuses most strongly on the contemporary situation, the greatest effort should be placed on the coding of more recent articles and documents. Coding should work backwards in time, starting from latest articles and proceeding to older ones. 


\subsubsection{Coding quality control}

After about 20 articles have been coded, someone else should also code them, to check the reliability of coding methods. If the two coders do not code the articles in the same way, the coding method, instructions and training must be refined.

\subsubsection{Codebook sections}

The media coding consists of five main parts: (1) coding of descriptive variables, (2) coding of variables identifying the primary and secondary frames, (3) protest event analysis, (4) policy events analysis, and (5) policy actor variables. Please see the Code Book for further details.

The five elements of the media frame analysis are: 1. Descriptive variables (Level 1). These are variables that simply identify the article. Data about the page number, section in the newspaper and the type of article will also give different indications of the importance of the article, and can provide interesting insights on the changes in coverage of REDD+ issues over time and across countries. Level 1 coding is applied to all articles in the database.

\section{Variables analysing the primary and secondary} frames (levels 2 and 3). These variables analyse the primary and secondary media frames. Level 2 coding identifies four characteristics of the primary and secondary frame: type of frame, level of the frame, metatopic of the frame, and topic of the frame. Level 2 coding is sufficient if the interest is in a quick identification of the main topics reported in news articles.

Level 3 coding identifies the primary and secondary frames in much more detail. It includes identification of the main advocates and adversaries, their stances and ideological position, and types of actions. Level 3 coding is much more intensive and allows a more detailed identification of the main discourses that are used to represent ideological positions and beliefs. It identifies advocates and adversaries within the frames and better qualifies their positions. This level of analysis allows identification of different interests and later analysis of coalitions advocating different approaches to REDD issues.

Depending on the total number of articles selected through the REDD keyword search, Level 3 analysis may be undertaken on all or a random sample of articles. If the average number of articles is less than or equal to 20 per newspaper per year (60 articles per year), Level 3 coding should be done on all articles. If the selection is much larger, Level 3 coding should be undertaken only for a subsample of the articles identified. The subsample must be selected chronologically, in order to reflect the same intensity of reporting over time as the population. The easiest way to do this is to select every Xth article, appearing chronologically, where $\mathrm{X}$ can be from 2-5 depending on the total number of articles and resources available for the analysis. At least $20 \%$ of the total population should be covered.

The following element ( $3-5$ below) can be assessed for all articles (best option) or for the subsample selected for Level 3 coding. Whichever approach is taken, it must be documented.

3. Protest events. Media coverage is routinely used to identify the main environmental protest events (Rootes 2006). This group of variables is based on what is written in each article as a whole (not on single frames). The work requires checking each article for indication of protest events and identifying certain characteristics of the events. We use the broad definition of environmental protest events presented in Fillieule and Jimenez (2006), where an environmental protest event is defined as 'a collective, public action regarding issues in which explicit concerns about the environment [in our case REDD] are expressed as a central dimension, organized by non-state instigators with the explicit purpose of critique or dissent together with societal and/or political demands'.

4. Policy events. This group of variables relate to policy events; they include the type of event, and responses to it. As with the protest event coding, policy event coding is based on what is written in each article as a whole (not on single frames). We define a policy event as 'a critical, temporally located decision point in a collective decision-making sequence that must occur in order for a policy option to be finally selected' (Laumann and Knoke 1987). Each article is scanned for relevant events.

5. Policy actors. This process identifies all other relevant core policy actors mentioned (apart from the earlier mentioned advocates and adversaries of the two main frames). We define a core actor 
as 'an organisation or an individual that defines themself and is perceived by others as a part of the national policy domain'. This list of core actors will contribute to the identification of all relevant (mainly organisational) actors which are active in the REDD policy domain. These actors, or a subsection of them, will become part of the respondents to the Social Organisation Network Survey.

\section{Code book}

\section{Variables and codes: Derivations and meaning}

\subsection{Descriptive variables}

\section{(Level 1 coding)}

The first set of variables are descriptive, enabling us to identify the article. However, data about the page number, section in the newspaper and the type of article will give additional indications of the importance of the article.

Coder_ID. Use this variable to identify who has coded each case. You can use the initials of the coders name followed by a sequential number, both of which uniquely identify the coder (e.g. if Coder 1 is Melanie Brown, her Coder_ID will be MB1).

Coder_name. Use this variable to enter the related full name (e.g. Coder_name: Melanie Brown).

Article_ID. This is the same article identity code that you assigned to the article when you constructed the database. The code should follow the format: year/ month/day/newspaper abbreviation/page number of article/order on page (if two or more articles) (e.g. 20090101JP1a).

Newspaper. This variable will need to be coded according to the newspapers you have selected:

1. first newspaper name

2. second newspaper name

3. third newspaper name
Day. Choose a code for the day of the week:

1. Monday

2. Tuesday

3. Wednesday

4. Thursday

5. Friday

6. Saturday

7. Sunday

Page. Add the page number on which the article begins.

Section. This is currently a string variable, in which you type the section of the newspaper in which the article appears. Is it, for example, in the 'home', 'international', 'features' or 'business' section? Once we know all possible options, this can be recoded as a numeric variable.

Date. Add the date in which the article was published. Use the following format: DD-month abbreviation-YYYY (e.g. 31-Jan-2009).

Words. Enter the word length of the article.

Type. Choose a code for the type of article being analysed:

1. news

2. feature

3. letter

4. news summary

5. editorial

Author. Add the name of the author of the article if available (being sure to get the spelling correct).

Headline. Copy and paste the headline of the article into this string variable.

Passing. Does the article make only a passing reference to REDD?

1. Yes

2. No

If yes, no further coding is required. 


\subsection{Variables analysing the primary and secondary frames}

\section{(Level 2 coding)}

The second set of variables analyse the primary and secondary frames for each article.

A media frame is "a broad organizing theme for selecting, emphasizing, and linking the elements of a story such as the scenes, the characters, their actions, and supporting documentation" (Bennet, 2002:42 cited in Boykoff 2008 ).

In the database, variables prefixed with $\mathrm{F} 1$ refer to analysis of the primary frame and variables prefixed with F2 refer to analysis of the secondary frame.

Note that when a secondary frame has not been identified (F2_PRESENCE=No), the rest of the variables in this section are coded as 'There is no F2' or 'Not applicable' (the related code stored in the database is '999') when they refer to the secondary frame.

\section{F1/F2type}

What aspect of the issue does the frame refer to? You may only select one code from the following list:

1. Diagnostic. Identifies a problem or issues and often who or what is to blame for the problem (related to REDD), including dismissing the reality of the problem altogether.

2. Prognostic. Involves the articulation of a proposed solution to the problem, or at least a plan of attack, and the strategies for carrying out the plan.

3. Symptomatic. Identifies why an issue is a problem, often by discussing the consequences of a problem. For instance, the effects of policies on emission reduction, ecological systems and the consequences for communities etc.

4. Motivational. Going beyond the basic existence of the issue and its causes and consequences, puts forward moral and motivational reasons why the speaker and/or others should be concerned about the problem and take action on it or ignore it. It tries to rally the reader behind a cause in relation to REDD.
5. Other. It approaches the issue differently from the above choices. This should be used only if none of the above applies. Most frames should fit options 1-4.

999. (For F2 variables only) Not applicable. There is no F2.

! NOTE: Excess coding as 'other' should be avoided.

\section{F1/F2level}

The codes in this variable fall into three categories, and refer to the scale of the political system to which the frame mainly refers, in relation to REDD issues:

1. International. Mainly concerned with REDD within an international global framework (e.g. issues related of the global REDD framework, United Nations Framework Convention on Climate Change (UNFCCC) negotiations and global climate change regime, global concerns related to REDD).

2. National. Mainly concerned with national issues related to REDD (e.g. national policymaking, assessment of existing national conditions, implementation issues, national public opinion).

3. Subnational. Mainly concerned with subnational issues. Can refer to the state level for federal systems; or regions, provinces or districts which have some autonomy in decision making (e.g. reporting on problems at the subnational level with particular policy conditions related to REDD, or about concerns or policies of subnational governments).

4. Local. Mainly concerned with local issues (e.g. reporting on specific problems at the local level, local incidents related to REDD, or about concerns of local actors).

999. (For F2 variables only) Not applicable. There is no F2.

\section{F1/F2metatopic}

1. Ecology. The frame refers mostly to ecological or 'green' issues, such as forests, plants, biodiversity, conservation and forest protection, or $\mathrm{CO}_{2}$ emissions/stocks/sequestration in relation to deforestation and forest degradation. 
2. Economics and markets. The frame refers mostly to economic issues, such as industry, commerce, markets - including carbon markets, business groups, business lobbyists, specific products or spokespeople of business interests. This includes the economic impacts on society.

3. Politics and policymaking. The frame refers mostly to individuals, processes or claims of governments and other political actors (parties), whether international, national, opposition, the civil service, quasi nongovernmental organisations or local authorities. This includes policy design and implementation.

4. Civil society. The frame refers mainly to civil law claims and rights, campaigns and protests -demonstrations, direct action, public opinion polls and consumer reports.

5. Governance context. The frame refers mainly to general governance conditions (corruption, law enforcement, monitoring and verification mechanisms) in a country and their implications for reducing emissions through avoided deforestation and forest degradation.

6. Science. The frame refers mostly to discoveries, innovative studies and release of scientific reports on applied science and new technologies. This category includes discussion of any scientific findings, scientific controversy, change in science or science reports.

7. Culture. The frame refers mostly to lifestyles, practices of individuals and community living, consumption patterns and popular culture.

8. Other. This applies to any other metatopic not captured above. Use this category sparingly, only if none of the others apply.

999. (For F2 variables only) Not applicable. There is no F2.

! NOTE: Excess coding as 'other' should be avoided.

\section{F1/F2topic}

The topics fall under 7 broad metatopics categories(and 3 sub-metatopics) which are indicated with letters below. The numbers represent the possible coding options of the single topics which should be entered in the database. Select only one of these for the topic of the primary and secondary frame respectively.

\section{A. Ecology}

Forest:

1. Deforestation. Related to ecology of deforestation in reference to carbon emissions (e.g. as a consequence of clear felling, fires and conversion to other uses).

2. Degradation. Related mainly to ecology of degradation of forests in reference to carbon emissions (e.g. as a consequence of selective logging or fires).

3. Forest conservation. Related mainly to ecology of forest conservation in reference to carbon stock enhancement.

4. Enhancement of forest carbon stocks. Refers to forest restoration and regeneration.

5. Sustainable forest management. Mainly related to technical issues of sustainable forest management practices, such as reduced impact logging and timber certification.

6. Afforestation and reforestation. Refers to planting of new forests (includes tree plantations) on lands that historically have not contained forests, and to schemes currently included in Clean Development Mechanism initiatives.

\section{Agriculture:}

7. Small-scale agricultural management systems. Refers to the ecological characteristics of smallscale agriculture, agroforestry schemes, limits and opportunities to reduce emissions.

8. Large-scale agriculture and livestock management systems. Refers to the ecological characteristics of large-scale agribusinesses and livestock systems, limits and opportunities to reduce emissions.

\section{Biodiversity:}

9. Biodiversity conservation. Focusing mainly on conservation of biodiversity as a co-benefit or as opposed to carbon sequestration.

\section{Other:}

10. Other major ecological concerns. Any other major ecological concern not captured above.

\section{B. Economics and markets}

11. Funding. Refers to issues related to funding of REDD+ processes, donors, and design and implementation of financial mechanisms. 
12. Carbon trading. Refers to intermediation and trading of carbon credits from REDD+. Can include creating REDD+ projects for carbon trading. Can also include business related profitmaking activities in carbon trading.

13. Cost-efficiency of REDD+. Refers to considerations related to reducing or containing costs (including transaction costs). Can refer to preparedness activities, as well as REDD+ schemes.

14. Economics and business. Refers to other economic issues, such as effects on the economy in general or economic interests of business, or specific companies.

\section{Politics and policymaking Elite politics:}

15. International organisations and political debates. Refers to the politics of UNFCCC meetings where REDD+ issues are discussed, and the position of different countries or country coalitions aimed at influencing public opinion or national policies.

16. State and bureaucratic interests. Refers to statements on a government agency agenda, state interests often represented in bureaucracies, struggles between and with state agencies on REDD+ issues - to protect or expand spheres of influence.

17. Business interests. Refers to industries opposing or promoting REDD+ in order to gain financially (or reduce losses) from REDD+ schemes.

\section{Policymaking:}

Design of REDD+ strategy/policies:

Refers to the policymaking process related to REDD+, from agenda setting to policy formulation, including design of demonstration activities and monitoring, reporting and verification (MRV) processes, and REDD+ sectors.

18. REDD+ readiness activities (activities for readiness not primarily linked to a specific REDD+ locality, for example institutional changes, capacity building, etc.)

19. Forest policies/policy reform

20. Agricultural and agribusiness policies/ policy reform

21. Demonstration activities (activities related to pilot projects in specific localities)
23. Infrastructure policies/policy reform (road building etc.)

24. Energy policies/policy reform

25. Industrial sector policies/policy reform

26. Decentralisation/regional autonomy policies/ policy reform

27. Land tenure policies/policy reform

28. Indigenous rights policies/policy reform

29. Carbon tenure policies

30. Policy reforms in other sectors (e.g. elimination of perverse incentives/subsidies)

Policy implementation:

(refers to implementation of national REDD+ policy strategy)

\section{REDD+ readiness activities}

32. Forest policies/policy reform

33. Agricultural and agribusiness policies/ policy reform

34. Demonstration activities

35. MRV policies

36. Infrastructure policies/policy reform (road building etc.)

37. Energy policies/policy reform

38. Industrial sector policies/policy reform

39. Decentralisation/regional autonomy

40. Land tenure policies

41. Indigenous rights policies/policy reform

42. Carbon tenure policies

43. Policy reforms in other sectors (e.g. elimination of perverse incentives/subsidies)

Policy coordination and participation:

44. Intermediation and coordination. Refers to efforts or concerns about coordination of sectoral government agencies, or coordination across levels (national, subnational, local).

45. Stakeholder consultation. Refers specifically to efforts or concerns to ensure inclusion and participation of multiple stakeholders in policy discussions.

Equity and distributional issues:

46. Benefit-sharing. Refers to the policy discussions on rights to carbon and decisions on benefit sharing mechanisms across stakeholders for REDD+ schemes. 


\section{Civil society}

47. Civil society interests. Refers to statements, positions and release of reports from civil society actors.

48. Campaigns/protest. Refers to expressly politically oriented protest actions and responses of citizens and civil society organisations (e.g. demonstrations, direct action, email campaigns).

49. Civil law. Involving a civil law claim, and class actions related to issues relevant to REDD+.

\section{E. Governance}

50. Illegal logging. Refers to law enforcement issues related to logging activities, international trade, monitoring and verification of certification etc.

51. Governance for effective MRV. Refers to governance issues related to MRV of carbon emissions reduction in REDD+ schemes.

52. Governance of carbon markets. Refers to governance issues related to fraudulent activities and lack of transparency and law enforcement in carbon markets.

53. Governance of international funds for REDD+. Refers to governance of funds provided by the international community at the national and subnational level, and to lack of transparency and law enforcement in administration of these funds.

54. Corruption. Refers to corrupt and collusive practices (involving illegal activities on the part of government officials) and related law enforcement issues.

55. Other law enforcement. Refers to issues of implementation and enforcement of criminal law other than those indicated in the above categories.

\section{F. Science}

\section{Scientific funding and processes}

57. New scientific methods, fundamentals, new studies

58. Applied science, new technologies (e.g. measuring degradation)

\section{G. Culture}

59. Knowledge and public understanding. Refers to knowledge, education and public opinion (poll results, consumer reports).
60. Lifestyle. Refers to practices of individual and community living, and consumption patterns.

61. Official national culture. Refers to ideas and symbols of nation identity.

62. Minority culture. Refers to minority cultural groups.

63. Popular culture. Refers to celebrities, films and books.

99. In case the F1/F2 metatopic falls under 8 .

'Other'.

999. (For F2 variables only) Not applicable. There is no F2.

\section{F1/F2KEYWORD1 and F1/F2KEYWORD2}

These two string variables each contain one keyword. Manually enter the two keywords (one in each variable field) that most clearly represent the related frame. This can be quantitatively coded at a later date, if appropriate.

\section{F2_presence}

Was it possible to identify a secondary frame? A secondary frame will not be identifiable in all cases. Simply code:

1. Yes

2. No

\section{Level 3 coding}

Level 3 coding will be undertaken for the primary frame and if present, for the secondary frame as well. First complete the primary frame, then move on to the secondary frame.

NOTE: Most short articles only have one primary frame.

\section{F1/F2advocate}

Is there an advocate for F1/F2?

1. Yes

2. No

999. (For F2 variables only) Not applicable. There is no F2. 
! NOTE: This concerns advocates and adversaries of the frame and not of REDD+.

\section{F1/F2FUT_ADVOC}

What assessment of the future does the advocate offer in relation to the REDD+ schemes and policies?

1. Optimistic. REDD+ schemes and policies are likely to have mainly positive outcomes, and are thus desirable. Reflects the position of supporters of REDD+ schemes and policies.

2. Pessimistic. REDD + schemes and policies are likely to have mainly negative outcomes, and are thus undesirable. Reflects the position of sceptics of REDD+ schemes and policies.

3. Neutral. REDD+ schemes and policies are likely to result in a mix of positive and negative outcomes.

4. No outlook. No view is expressed about the prospects for future outcomes of REDD+ schemes and policies.

99. Not applicable. There is no advocate for F1/F2.

999. (For F2 variables only) Not applicable. There is no F2.

\section{F1/F2OUT_ADVOC}

What is the main concern of the frame advocate in terms of REDD+ policy outcomes?

1. Effectiveness. The advocate of the frame is mainly concerned with issues related to effective reduction of $\mathrm{CO}_{2}$ emissions from deforestation and forest degradation.

2. Efficiency. The advocate of the frame is mainly concerned with issues related to cost-efficiency of REDD+ strategies and policies. Efficiency refers to whether the given emission reduction is achieved at the lowest possible cost.

3. Equity. The advocate of the frame is mainly concerned with fair distribution of benefits and costs, livelihoods and poverty reduction, and protection of rights (e.g. indigenous communities). ${ }^{2}$

4. Other co-benefits. The advocate of the frame is mainly concerned with other co-benefits (not

2 For more extensive definitions of "effectiveness", "efficiency" and "equity" please see Angelsen and Wertz-Kanounnikoff 2008. included under equity). These co-benefits mainly include benefits related to economic development and biodiversity.

5. Other. No major concern is stated in relation of effectiveness, cost-efficiency or equity.

99. Not applicable. There is no advocate for F1/F2.

999. (For F2 variables only) Not applicable. There is no F2.

\section{F1/F2TYPE_ADVOC}

What is the nature of the individual or group most closely associated with the promotion of the frame (in the case of the primary frame this actor is the 'primary definer')? Add a code from the following list:

1. National level state and bureaucratic actors. Individuals from, or views attributed to, organisations involved with government and state administration mainly at the national level, the civil service, and quasi-autonomous nongovernmental organisations (NGOs).

\section{Subnational or local level state and} bureaucratic actors. Individuals from, or views attributed to, organisations involved with government and state administration at subnational or local level, or local authorities.

3. Legal. Spokespeople from, or views attributed to, legal organisations (e.g. police, prosecutors).

4. Trade union. Spokespeople from, or views attributed to a trade union or group of unions based on a specific profession (e.g. The National Union of Miners).

5. Farmers' federation or farmers' group. Spokespeople from, or views attributed to, farmers' groups or federations.

6. Indigenous organisations. Spokespeople from, or views attributed to, indigenous organisations (based on ethnic minority identity).

7. Domestic NGO or NGO coalition. Spokespeople from, or views attributed to, NGOs without a primary environmental commitment (gender, poverty, development etc.).

8. Domestic environmental NGO or environmental NGO coalition. Spokespeople from, or views attributed to, environmental NGOs. 
9. International NGO. Spokespeople from, or views attributed to, international NGOs without a primary environmental commitment (e.g. Christian Aid, Oxfam).

10. International environmental NGO.

Spokespeople from, or views attributed to, international environmental NGOs (e.g. Friends of the Earth, World Wide Fund for Nature).

11. National private business. Spokespeople from, or views attributed to, single domestic companies or industry representatives.

12. Multinational corporation. Spokespeople from, or views attributed to, multinational or transnational companies or industry representatives.

13. Business association. Spokespeople from, or views attributed to, associations representing companies of a specific industrial sector (e.g. Association of Pulp and Paper Industries).

14. National research centre/think tank/ educational institution. Researchers from, or views attributed to, a university, research institution, think tank, or other education organisation.

\section{International research centre/think tank/} educational institution. Researchers from, or views attributed to, an international research institution, think tank, or foreign education organisation (CIFOR, Winrock International, Oxford University).

16. Intergovernmental organisations and bodies. Spokespeople or statements from an organisation primarily comprised of or controlled by sovereign states (referred to as member states) (UNFCCC, World Bank, Intergovernmental Panel on Climate Change).

17. Individual. An individual advocate with no identifiable organisational or sector affiliations.

No advocate. No identifiable frame advocate. This is likely to be the case for editorials and summary articles.

999. (For F2 variables only) Not applicable. There is no F2.

\section{F1/F2ADVOC_ORG}

This is a string variable. Type in the name of the advocate organisation, when appropriate. Be careful to spell the name correctly.

\section{F1/F2ADVOC_IND}

This is a string variable. Type in the name of the advocate individual, if appropriate. Be careful to spell the name correctly.

\section{F1/F2ADVOC STANCE}

This is a string variable. Using only a few words, please give some contextual information to define the demands, or preferred policy options expressed by the advocate. Present it as a stance which an audience can agree or disagree with. If a clear stance is present in the written text, you can cut and paste the statement.

A stance is a positional statement, which is purposefully phrased and facilitates a response either in agreement or disagreement (non-neutral statements).

\section{F1/F2ADVERSARY}

Is there an adversary for F1/F2?

1. Yes

2. No

999. (For F2 variables only) Not applicable. There is no F2.

! NOTE: This concerns advocates and adversaries of the frame and not of REDD+.

\section{F1/F2FUT ADVER}

What assessment of the future does the adversary offer in relation to the REDD+ schemes and policies?

1. Optimistic. REDD+ schemes and policies are likely to have mainly positive outcomes, and are thus desirable. Reflects the position of supporters of REDD+ schemes and policies.

2. Pessimistic. REDD+ schemes and policies are likely to have mainly negative outcomes, and are thus undesirable. Reflects the position of sceptics of REDD+ schemes and policies. 
3. Neutral. REDD+ schemes and policies are likely to result in a mix of positive and negative outcomes.

4. No outlook. No view is expressed about the prospects for future outcomes of REDD+ schemes and policies.

99. Not applicable. There is no adversary for F1/F2.

999. (For F2 variables only) Not applicable. There is no F2.

\section{F1/F2OUT_ADVER}

What is the main concern of the frame adversary in terms of REDD+ policy outcomes?

1. Effectiveness. The adversary of the frame is mainly concerned with issues related to effective reduction of $\mathrm{CO}_{2}$ emissions from deforestation and forest degradation.

2. Efficiency. The adversary of the frame is mainly concerned with issues related to cost-efficiency of REDD+ strategies and policies. Efficiency refers to whether the given emission reduction is achieved at the lowest possible cost.

3. Equity. The adversary of the frame is mainly concerned with fair distribution of benefits and costs, livelihoods/poverty reduction, protection of rights (e.g. indigenous communities).

4. Other co-benefits. The adversary of the frame is mainly concerned with other co-benefits (not included under equity). These co-benefits mainly include benefits related to economic development and biodiversity.

99. Not applicable. There is no adversary for F1/F2.

999. (For F2 variables only) Not applicable. There is no F2.

\section{F1/F2TYPE_ADVER}

What is the nature of the individual or group most closely associated with the opposition to the advocated position? Use a code from the following list:

\section{National level state and bureaucratic actors.}

Individuals from, or views attributed to, organisations involved with government and state administration mainly at the national level, the civil service, and quasi-autonomous nongovernmental organisations (NGOs).

\section{Subnational or local level state and} bureaucratic actors. Individuals from, or views attributed to, organisations involved with government and state administration at subnational or local level, or local authorities.

3. Legal. Spokespeople from, or views attributed to, legal organisations (e.g. police, prosecutors).

4. Trade union. Spokespeople from, or views attributed to, a trade union or group of unions based on a specific profession (e.g. The National Union of Miners).

5. Farmers' federation or farmers' group. Spokespeople from, or views attributed to, farmers' groups or federations.

6. Indigenous organisations. Spokespeople from, or views attributed to, indigenous organisations (based on ethnic minority identity).

7. Domestic NGO or NGO coalition. Spokespeople from, or views attributed to, NGOs without a primary environmental commitment (gender, poverty, development etc.).

8. Domestic environmental NGO or environmental NGO coalition. Spokespeople from, or views attributed to, environmental NGOs.

9. International NGO. Spokespeople from, or views attributed to, international NGOs without a primary environmental commitment (e.g. Christian Aid, Oxfam).

10. International environmental NGO. Spokespeople from, or views attributed to, international environmental NGOs (e.g. Friends of the Earth, World Wide Fund for Nature).

11. National private business. Spokespeople from, or views attributed to, single domestic companies or industry representatives.

12. Multinational corporation. Spokespeople from, or views attributed to, multinational or transnational companies or industry representatives.

13. Business association. Spokespeople from, or views attributed to, associations representing companies of a specific industrial sector (e.g. Association of Pulp and Paper Industries). 


\section{National research centre/think tank/} educational institution. Researchers from, or views attributed to, a university, research institution, think tank, or other education organisation.

15. International research centre/think tank/ educational institution. Researchers from, or views attributed to, an international research institution, think tank, or foreign education organisation (CIFOR, Winrock International, Oxford University).

16. Intergovernmental organisations and bodies. Spokespeople or statements from an organisation primarily comprised of or controlled by sovereign states (referred to as member states) (UNFCCC, World Bank, Intergovernmental Panel on Climate Change).

17. Individual. An individual advocate with no identifiable organisational or sector affiliations.

99. No adversary. No identifiable frame adversary. This is likely to be the case for editorials and summary articles.

999. (For F2 variables only) Not applicable. There is no F2.

\section{F1/F2ADVER_ORG}

This is a string variable. Type in the name of the adversary organisation, when appropriate. Be careful to spell the name correctly.

\section{F1/F2ADVER_IND}

This is a string variable. Manually enter the name of the adversary individual, when appropriate. Be careful to spell the name correctly.

\section{F1/F2ADVER_STANCE}

This is a string variable. Using only a few words, give some contextual information to define the demands, or preferred policy options expressed by the adversary. Present it as a stance which an audience can agree or disagree with. If a clear stance is present in the written text, you can cut and paste the statement.

A stance is a positional statement, which is purposefully phrased and facilitates a response either in agreement or disagreement (nonneutral statement).

\subsection{Protest event analysis}

The third group of variables comprise a protest event analysis, based on what is written in each article as a whole (not within each frame).

Following Fillieule and Jimenez (2006), we define environmental protest events as 'a collective, public action regarding issues in which explicit concerns about the environment [in our case REDD+] are expressed as a central dimension, organized by nonstate instigators with the explicit purpose of critique or dissent together with societal and/or political demands'.

Does the article mention protest?

1. Yes

2. No

The following variables refer to the totality of protest events identified in the article. One protest event can include different types of protests, or less often an article might report multiple protests of different types. These cases will be coded in the same way, by simply identifying all different types of protests mentioned in the article.

\section{PRO_CONV}

If protest was mentioned, did the article refer to conventional protest? Conventional protest includes 'demands for judicial review, actions such as collective representations to officials or elected politicians, public meetings, leafleting and the collection of signatures on petitions' (Rootes 2006).
1. Yes
2. No

99. No protest mentioned.

\section{PRO_ATTA}

If protest was mentioned, did the article refer to an attack on property? These are defined as minor attacks on property that do not pose a threat to human life. This can include theft (Rootes 2006).
1. Yes
2. No 
99. No protest mentioned.

\section{PRO_CONF}

If protest was mentioned, did the article refer to confrontational protest? This includes blockades, or occupations of buildings or land.

1. Yes

2. No

99. No protest mentioned.

\section{PRO_DEM}

If protest was mentioned, did the article refer to demonstrative protest? This means street marches, demonstrations, vigils and rallies.

1. Yes

2. No

99. No protest mentioned.

\section{PRO VIOL}

If protest was mentioned, did the article refer to violent protest. This is defined as 'attacks on persons whether or not they cause actual injury, and including any attacks on property that might be potentially life threatening' (Rootes 2006).

1. Yes

2. No

99. No protest mentioned.

\subsection{Policy event analysis}

A policy event represents an important milestone in the making of domestic REDD+ policy.

\section{DOM_MOMENT}

Does the article mention a domestic policy event?

1. Yes

2. No

\section{DOM_MOMENT_TYPE}

What is the nature of the domestic policy event?

1. Government announcement of a policy decision.

2. Political actor pushing for a specific policy proposal/option.

3. Release of an influential policy or research document on REDD+ from a government agency, a research institute or an influential NGO.

4. Consultation on pending legislation.

5. Passage of a bill or enactment of a new regulation.

6. Prime (or other) minister landmark speech on REDD+.

7. Other.

99. Not applicable.

\section{DOM_EVENT_DETAILS}

This is a string variable. Using only a few words, please give some contextual information to define the policy decisions or policy options that are discussed. Present it as a stance which an audience can agree or disagree with.

\section{INT_MOMENT}

Is there an international policy event? These are milestones in international politics that bear upon domestic politics. We assume that all international political events involving REDD+ reported in national newspapers have domestic relevance.

1. Yes

2. No

\section{INT_TYPE}

What is the nature of the international policy event?

1. A landmark speech made by a minister from another country, or other international actor (e.g. UN Secretary General, World Bank).

2. The passage or implementation of legislation in another country.

3. A Conference of the Parties meeting and/or related decision point.

4. A Gn summit.

5. An EU summit.

6. Another international meeting/summit.

7. Other.

99. Not applicable.

\section{INT_MOMENT_DETAILS}

This is a string variable. Using only a few words, please give some contextual information to define the main policy decisions or policy options represented by the international policy event. This can then be coded at a later stage if necessary. 


\section{INT_RESPONSE}

Is there a domestic response to the international policy event?

1. Yes

2. No

The following string variable aims to assess the nature the domestic response to the international policy event.

\section{INT_RESPONSE_DETAILS}

This is a string variable. Using only a few words, please give some contextual information to define the government response to the international policy event. Present this as a stance, which an audience can agree or disagree with. This can then be coded at a later stage if necessary.

\subsection{Policy actor list}

Next identify any other actor mentioned in the article that appears to be relevant in the REDD+ debate addressed in the article. Do not include the advocate and adversary, as these have been identified earlier. For each different actor enter the following four variables.

\section{ORGNAME}

This is the preferred entry for actors, which is the name of the organisation to which she/he belongs (e.g. ORGNAME: World Wildlife Fund for Nature).

\section{ACRONYM}

If the organisation is mentioned by its acronym specify it (e.g. ACRONYM: WWF).

\section{PERSON}

In some cases, actors are single individuals mentioned only by their name. In which case, enter the full name of the person (e.g. PERSON: Leslie Jones).

\section{POSITION}

In some cases a position in the organisation is mentioned, as is often the case for high-ranking government officials (e.g. POSITION: Deputy Chief Executive).

Among these four identifiers, enter all those that are indicated in the article. Leave those fields blank for which the information is not provided in the article. Be careful to spell the names correctly.

\section{References}

Angelsen, A. and Wertz-Kanounnikoff, S. 2008 What are the key design issues for REDD+ and the criteria for assessing options? In: Moving ahead with REDD+, 19-21. CIFOR, Bogor, Indonesia.

Boykoff, M. 2007 Flogging a dead norm? Newspaper coverage of anthropogenic climate change in the United States and United Kingdom from 2003 to 2006. Area 39(2).

Boykoff, M. 2008 The cultural politics of climate change discourse in the UK tabloids. Political Geography 27:549-569.

Boykoff, M. and Mansfield, M. 2008 Ye olde hot aire: Reporting on human contributions to REDD+ in the UK. Environmental Research Letters 3:1-8.

Fillieule, O. and Jimenez, M. 2006 The methodology of protest event analysis. In: Rootes (ed.)

Environmental protest in Western Europe. Oxford University Press, Oxford, UK. p 258-279.

Laumann, E. O., and Knoke, D. 1987 The organizational state: Social choice in national policy domains. Madison, WI and London: the University of Wisconsin Press.

Rootes, C. (ed.) 2006 Environmental protest in Western Europe. Oxford University Press, Oxford, UK.

\section{Acknowledgements}

This research is part of the policy component of the Center for International Forestry Research (CIFOR) Global Comparative Study (GCS) (http://www. forestsclimatechange.org/global-comparative-studyon-redd.html), led by Maria Brockhaus. The methods applied in this study build on research undertaken by the Comparing Climate Change Policy Networks (COMPON) programme funded by the National Science Foundation (NSF) and led by Jeffrey Broadbent at the University of Minnesota. Monica Di Gregorio and Maria Brockhaus adapted the Protocol for Media Analysis developed by COMPON. Among many other COMPON members, we would like to thank Stephan Price and Clare Saunders for sharing the 'Code book for the analysis of media frames in climate change articles'.

Funding for CIFOR's research was provided the Norwegian Agency for Development Cooperation, the Australian Agency for International Development, the UK Department for International Development, the European Commission and the US Agency for International Development. 

This research was carried out by CIFOR as part of the CGIAR Research Programme, 'Forests, Trees and Agroforestry: Livelihoods, Landscapes and Governance'. The Programme aims to enhance management and use of forests, agroforestry and tree genetic resources across the landscape from forests to farms. The Center for International Forestry Research leads the collaborative Programme in partnership with Bioversity International, the International Center for Tropical Agriculture and the World Agroforestry Centre.

\section{圆}

NORWEGIAN MINISTRY OF THE ENVIRONMEN NORWEGIAN MINISTRY OF FOREIGN AFFAIRS

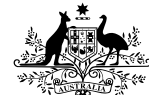

Australian Government

AusAID
DFID
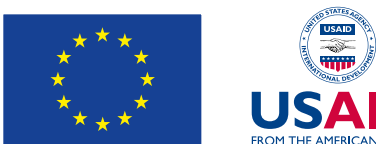

USAID

CIFOR advances human wellbeing, environmental conservation and equity by conducting research to inform policies and practices that affect forests in developing countries. CIFOR is a CGIAR Consortium Research Center. CIFOR's headquarters are in Bogor, Indonesia. It also has offices in Asia, Africa and South America. 